\title{
POST-IMPLEMENTATION EVALUATION OF A DIGITAL DICTATION SYSTEM IN A LARGE HEALTH SERVICE USING HOT- FIT FRAMEWORK
}

\author{
Christopher Bain', Aniruddha Goswami², Sheree Lloyd³, Laura Davis4 \\ 1. Monash University, Australia \\ 2. The Salvation Army Australia \\ 3. Griffith University, Queensland Australia \\ 4. Mercy Health, Australia
}

Correspondence: aniruddha_vg2@hotmail.com

\begin{abstract}
\section{OBJECTIVE:}

The objective of this study was to evaluate a digital dictation system (DDS) that has been implemented in a large health service. The data collected in this study was used to understand the overall uptake and performance of the system and consequently improve the quality of care delivered by the organisation.
\end{abstract}

\section{METHODS:}

A mixed method research design was used in this study. Clinicians and Medical Transcriptionists (MTs) using the DDS across the two campuses of the health service over a period of four months, were surveyed to assess the extent to which the implementation of the DDS is fulfilling its purpose. In addition, system usage statistics, project implementation documents and user support emails were also analysed.

\section{RESULTS:}

This study utilised an existing comprehensive and validated evaluation framework, the Human, Organisation and Technology Fit (HOT-Fit) framework. Human fit: $79.55 \%$ $(n=35)$ of Clinicians and $33.33 \%(n=2)$ of MTs reported an overall satisfaction with the DDS. Organisation fit: The document analysis revealed that the DDS selected aligned best with current organizational IT strategies and was an easy fit with existing practices. Technology fit: An overall satisfaction of $53.49 \%(n=23)$ from the Clinicians and $16.67 \%$ $(n=1)$ from the MTs was reported on the DDS. Out of 22 issues lodged regarding the system, $77.27 \%(n=17)$ issues met the Service Level Agreement (SLA).

\section{CONCLUSIONS:}

The overall findings of the study suggest that, the DDS was a good fit within the organisation in terms of Human fit and Organisation fit. In terms of Technology fit there existed some technical issues on the end-user level due to the system being new to the end users. To overcome this and facilitate the smooth functioning of the DDS, effective communication with the vendor and other relevant stakeholders was recommended so that end users i.e. the Clinicians and MTs understand the system, its functionality and their role in providing timely and high-quality information for clinical care.

\section{KEYWORDS}

post-implementation, evaluation, hot-fit framework, health information system, digital dictation system 
The implementation of health information systems (HIS) can have a profound impact on healthcare organisations and the delivery of health services. Using information and communications technology (ICT) in healthcare offers numerous opportunities to support healthcare professionals in their daily routine; for example accessibility to up-to-date patient information at the right time, to lower the risk of clinical errors, diagnostic and medication errors, and to augment the quality and efficiency of patient care. [1] The implementation of HIS also has associated threats. Contemporary HIS are expensive and failures in implementation may cause an adverse impact on the health care organisations and provision of health services. $[1,2]$ Consequently, systematic appraisal of these systems is imperative, in order to understand their true potential and safeguard the benefits that can be delivered over the long term.[3]

Findings from various studies on post-implementation evaluation of HIS have highlighted that a poor fit between human, organisation and technology factors were the main causes for adoption failures of HIS in hospitals.[ 4-7] Studies on implementation of HIS have been discussed extensively in the literature, but studies on postimplementation evaluation of HIS in terms of human, organization and technology fit are scarce.[8,9] To fill this gap, Yosuf and colleagues made a critical assessment of the existing literature on frameworks and models of evaluation of information systems. The result of their analysis was a comprehensive framework that can be used to evaluate HIS. This framework, around HIS 'fit' they termed: Human, Organisation and Technology Fit (HOT-Fit).[6]

The HOT-Fit framework is a combination of DeLone and McLean's Information System (IS) Success model and the IT Organisation fit model (also known as the MIT 90s model). The IS success model complements the IT Organisation fit model in fulfilling the limitations of the existing HIS evaluation frameworks. [2,6] This framework emphasises the significance of each of the Human, Organisation and Technology fit dimensions. It is flexible in its application and can be used to evaluate any HIS based on the type, context and relevance of the study.[6,10] According to Yosuf, "the framework can and should be applied in a flexible way, taking into account different contexts and purposes, stakeholders' point of views, phases in system development lifecycle and evaluation methods". [6] The concept of 'fit' in the HOT-Fit framework is often interpreted as intuitive, intricate and impressionistic. [6] It is associated with the competence and capability of the HIS, the human and the organisation to align with each other and can be analysed and measured through various factors such as System use, User satisfaction, System quality, Service quality, Organisational culture and Leadership support.[7]

The digital dictation system (DDS) that has been implemented in the study organisation accelerates the patient journey by speeding up the turnaround time (TAT) of outpatient letters, discharge summaries and operations reports. The improved turnaround ensures that vital clinical information is made available more quickly to inform ongoing management and care. The DDS plays a pivotal role in providing efficient, economic, and effective administrative services by maximising the use of technology and eliminating delays, waste and rework. The system can transfer dictation files electronically anywhere throughout the system. Automatic Speech Recognition (ASR) technology improves the accuracy of the system and decreases the requirement of re-dictation thus saving time.[11] The implementation was based on generating these benefits and a post-implementation evaluation was undertaken to inform improvements in the use of the system, identify issues with the service performance, and determine the effectiveness of the implementation.

The HOT-Fit framework used to evaluate the DDS was modified according to the context of this study, shown in Figure 1. 


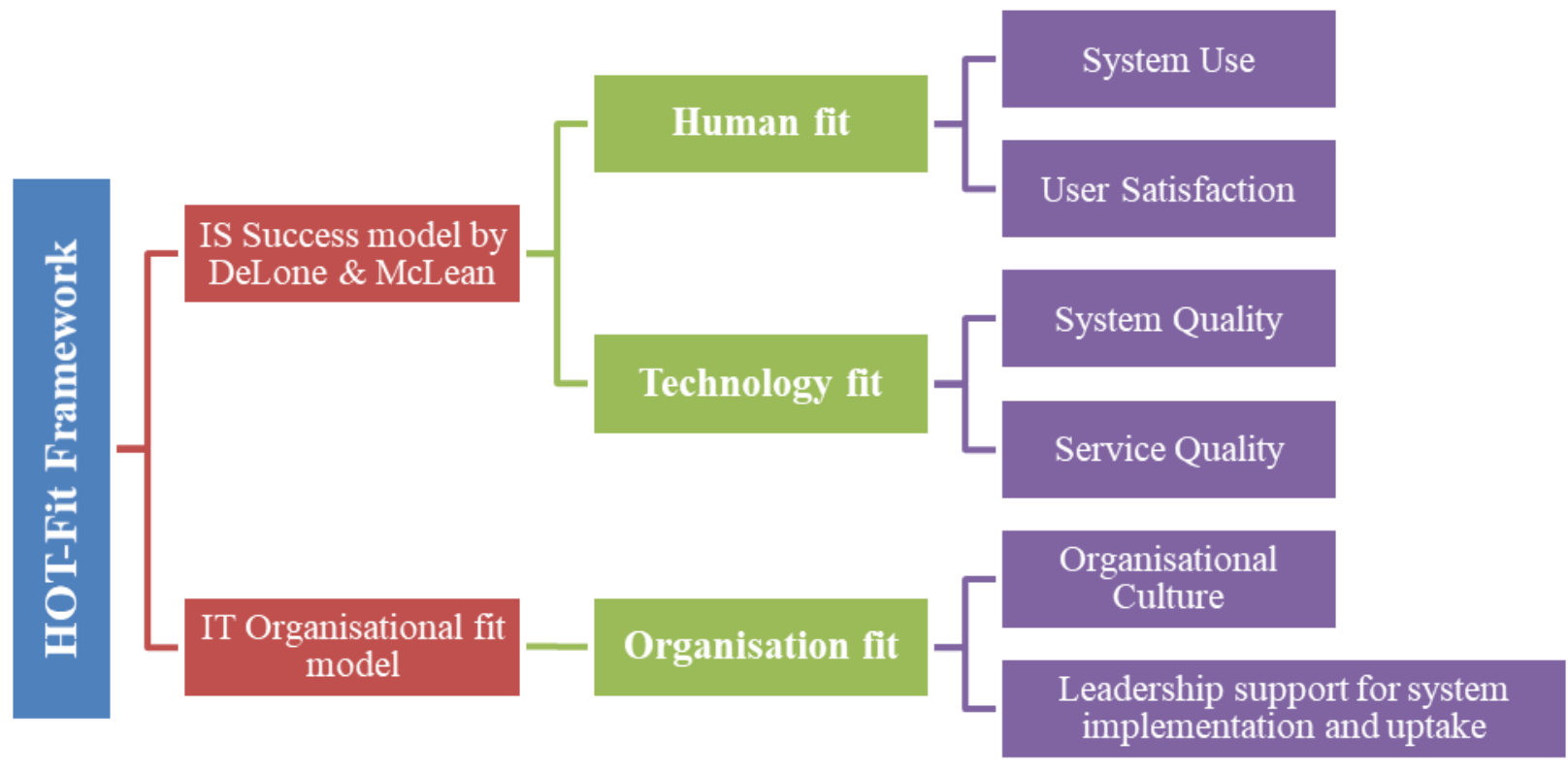

The Human fit dimension assists in gaining an understanding of how the system is used and user satisfaction. The Organisation fit dimension helps to explain how the DDS has been accepted and evaluates the support provided by the leaders to deploy the system in the organisation. While Technology fit dimension contributes in understanding and gauging the support provided by the teams responsible for looking after the system and ensuring service quality.

\section{METHODS}

\section{SETTING}

The study organisation operates several distinctively different services geographically distributed across Australia. The focus of this study was Hospital $1(\mathrm{H} 1)$ and Hospital 2 (H2) (same health service) in Victoria, Australia. $\mathrm{Hl}$ is one of Victoria's largest maternity hospitals with 229 beds and is a major teaching public hospital, a leader in women's health management, and a regional centre for neonatology, maternity, and general and specialty gynecology services. $\mathrm{H} 2$ is a general community public hospital with 200 beds located in one of the fastest growing municipalities of Victoria $\mathrm{H} 2$ provides various services, including general medical and surgery, palliative care, day chemotherapy, renal dialysis, allied and mental health services, rehabilitation programs, and a 24-hour emergency department, all in modern and comfortable surroundings.

\section{DESIGN}

A mixed method study design was considered for this research. Formal approval from the Human Research Ethics Committee (HREC) was granted as a 'low-risk' research study as the study was considered a routine HIS and health services evaluation and a quality improvement activity. No individual patient records were screened.

\section{DATA COLLECTION}

The study was conducted over a period of four months (second quarter of a calendar year). A survey instrument was designed using the dimensions of the HOT- Fit framework relevant to this study. It comprised of two branching arms to capture the responses of the Clinicians and Medical Transcriptionists (MTs) separately. The survey included questions related to the computer literacy skills and baseline comfort with technology. The questions were based on a validated and a reliable source called Use of Technology (UOT) component of the Technology and Internet Assessment (TIA) scales [12] Additional data collected include:

\section{- $\quad$ system usage statistics;}

- $\quad$ user support emails;

- project implementation documents;

- $\quad$ Service Level Agreement (SLA) with the vendor.

System usage statistics in $\mathrm{H} 1$ and $\mathrm{H} 2$ provided an estimate of the total amount of utilisation by the work type and an indication as to whether the system has fulfilled its purpose. 
Project implementation documents were analysed to understand the culture of the organisation and assess the Organisational fit in terms of change management and leadership support during the DDS implementation and uptake. While user support emails and the SLA were reviewed to determine the Technology fit by evaluating the system and service quality of the DDS. An overview of the study design is shown in Table 1 below.

\section{TABLE 1 - HUMAN, ORGANISATION AND TECHNOLOGY FIT (HOT-FIT) FRAMEWORK.}

AN OVERVIEW OF THE STUDY DESIGN BASED ON THE HOT-FIT FRAMEWORK

\begin{tabular}{|c|c|c|c|}
\hline DIMENSION & SUB-DIMENSION & TARGET & DATA TYPE \\
\hline \multirow[t]{2}{*}{ HUMAN FIT } & User satisfaction & Clinicians and MTs & User survey \\
\hline & System use & $\begin{array}{l}\text { Database of the } \\
\text { DDS. }\end{array}$ & $\begin{array}{l}\text { System usage statistics and volume of } \\
\text { total dictated jobs }\end{array}$ \\
\hline \multirow[t]{2}{*}{$\begin{array}{l}\text { ORGANISATION } \\
\text { FIT }\end{array}$} & $\begin{array}{l}\text { Leadership support for } \\
\text { the system } \\
\text { implementation and } \\
\text { uptake }\end{array}$ & $\begin{array}{l}\text { Clinicians and } \\
\text { Organisation. }\end{array}$ & $\begin{array}{l}\text { User survey and DDS project } \\
\text { implementation documents. }\end{array}$ \\
\hline & Organisational culture & $\begin{array}{l}\text { Clinicians and } \\
\text { Organisation }\end{array}$ & $\begin{array}{l}\text { User survey and DDS project } \\
\text { implementation documents. }\end{array}$ \\
\hline \multirow[t]{2}{*}{ TECHNOLOGY FIT } & System quality & Clinicians and MTs & $\begin{array}{l}\text { User survey, user support emails raised } \\
\text { to the support groups. }\end{array}$ \\
\hline & Service quality & Clinicians and MTs & $\begin{array}{l}\text { User survey, user support emails raised } \\
\text { to the support groups and the Service } \\
\text { Level Agreement (SLA). }\end{array}$ \\
\hline
\end{tabular}

\section{INCLUSION AND EXCLUSION CRITERIA (PARTICIPANTS AND RECRUITMENT PROCEDURE)}

The participants of the study were the Clinicians and MTs who were the key users of the DDS across the two hospital campuses of the health service $(\mathrm{H} 1$ and $\mathrm{H} 2)$. Those identified as active system users during a period of four months of the study were included and invited to complete the survey. Participants active or inactive beyond the four months' timeframe were excluded from the study to maintain the integrity of the research in terms of limited time and meticulous nature of the research.

From the total $100 \%(n=880)$ of the active and inactive user pool of the Clinicians, the sample was sized down to $25 \%$ $(n=220)$ with respect to the inclusion and exclusion criteria as active system users. While the total number of MTs' active user pool providing in-house transcription service was $(n=10)$ and were all included.

The final sample size of the study, i.e. $100 \% \quad(n=230)$ comprised of $95.65 \%(n=220)$ Clinicians and $4.35 \%(n=10)$
MTs. The survey was kept open for three weeks with a weekly reminder to the participants.

\section{DATA ANALYSIS}

Statistical analysis was performed for quantitative survey data, system usage statistics and volume of dictated jobs. To determine the correlation between different variables of the survey data, the Chi-square test was adopted. Cross tables were used to represent the relationship of the row variables with the column variables. Any missing observation was dropped from the analysis. The hypothesis that the variables depend on each other was tested against the null hypothesis of no dependence at a $5 \%$ significance level. In other words, if the variables are related, the probability of observing a relationship ( $p$-value) would be lower than $5 \%(0.05)$. If the variables are not related, the test would return a p-value larger than 0.05 and, therefore, a result that a statistically significant relationship does not exist can be concluded. However, it must be noted that the small sample size can be a threat to the validity of the test. 
A qualitative thematic analysis was carried out for open text answers, project implementation documents, user support emails and, the SLA by collating the data and identifying themes around the key issues identified by the stakeholders. Analysis of data was conducted using both, SurveyMonkey ${ }^{\mathrm{TM}}$ and Microsoft Excel ${ }^{\mathrm{TM}}$ software.

\section{RESULTS}

To address the aims of the study key demographic information and a synthesis of the findings of the dimensions of HOT fit framework are presented. Fifty-one users of the system responded to the survey, just over $22.17 \%$ of the initial sample. A sample of 44 healthcare professionals and 6 medical transcriptionists $(n=50)$ were analysed separately for their responses to certain relevant variables.

\section{DEMOGRAPHICS}

Of the 51 respondents, $62.75 \%(n=32)$ were female and $37.25 \%(n=19)$ were male with a mean ( \pm s.d.) age range of 35 to 44 ( \pm 11.7 ) years.
According to the data, $52.94 \%(n=27)$ held a graduate degree (masters or $\mathrm{PhD})$ and $33.33 \%(\mathrm{n}=17)$ held a bachelors' degree. Not all respondents indicated their employment status however $37.25 \% \quad(n=19)$ of the participants were permanent, part time employees; $25.49 \%$ $(n=13)$ were consultants, on-appointments for example sessional VMO; and $25.49 \%(n=13)$ had permanent, full-time employment status.

\section{Human Fit}

\section{a.) System Use:}

The DDS usage statistics to determine the volume of system usage by each specialty work type is explained in Table 2.

\section{b.) User Satisfaction:}

The survey results for Clinicians' user satisfaction showed $79.55 \%(n=35)$ overall satisfaction with the DDS. Detailed results on Clinician user satisfaction are represented in Section 3 (i.e. Table 3.1, Table 3.2 and Table 3.3). This contrasted with MTs' user satisfaction that showed only $33.33 \%(n=2)$ overall satisfaction with the DDS. Results are represented in Table 4.

\section{TABLE 2 - SYSTEM USE - ACCORDING TO WORK TYPE AND TURNAROUND TIME (TAT)}

TAT = time taken to dictate the patient information by the clinician till e-signing (finalizing) the letter/report in hours; $\mathbf{n}=$ total number of hours over the period of 4 months; Usage= The extent (based on ' $n$ ') of the DDS used by the Clinicians to dictate the patient information and to serve the purpose to fulfill the requirements of clinical standards of documentation of their specialty work type; Work Type= specialty services provided by $\mathrm{H} 1$ and $\mathrm{H} 2$.

\begin{tabular}{|c|c|c|}
\hline USAGE & PURPOSE & WORK TYPE AND TAT (N) \\
\hline $\begin{array}{l}\text { HIGH USAGE } \\
\text { (601 AND ABOVE) }\end{array}$ & Outpatient Letters & $\begin{array}{l}\text { Surgical Clinic ( } n=705) \\
\text { Urogynecology }(n=692) \\
\text { Paediatric Clinic }(n=670)\end{array}$ \\
\hline $\begin{array}{l}\text { MEDIUM USAGE } \\
(301-600)\end{array}$ & Outpatient Letters & $\begin{array}{l}\text { Endo-surgery B }(n=450) \\
\text { Gynaecology }(n=426) \\
\text { Orthopaedic ( } n=383) \\
\text { Perinatal Medicine }(n=343)\end{array}$ \\
\hline $\begin{array}{l}\text { LOW USAGE } \\
(0-300)\end{array}$ & $\begin{array}{l}\text { Outpatient Letters } \\
\text { Operations Report } \\
\text { Medico-Legal reports }\end{array}$ & $\begin{array}{l}\text { Perinatal Mental Health }(n=1) \\
\text { Gerontics }(n=2) \\
\text { Oncology }(n=1) \\
\text { Gerontics }(n=2)\end{array}$ \\
\hline
\end{tabular}


TABLE 3.1 - USER SATISFACTION: RESULTS OF CLINICIANS' SATISFACTION OF THE DDS UNDER HUMAN FIT OF THE HOT-FIT FRAMEWORK

\begin{tabular}{|l|l|l|l|l|}
\hline $\begin{array}{l}\text { FREQUENCY OF CURRENT } \\
\text { DDS USAGE? }\end{array}$ & \multicolumn{2}{l|}{ OVERALL SATISFACTION WITH THE CURRENT DDS } & TOTAL \\
\hline & Neutral & Satisfied & Dissatisfied & \\
\hline DAILY & 0 & 2 & 1 & 3 \\
\hline MANY TIMES IN A DAY & 0 & 3 & 0 & 3 \\
\hline ONCE IN A WEEK & 1 & 21 & 4 & 26 \\
\hline TOTAL & 1 & 26 & 5 & 32 \\
\hline
\end{tabular}

Pearson chi2 (4) = 1.5116; $\operatorname{Pr}=0.825$

Table 3.1 shows that no significant relationship exists between the frequency of use of the DDS and the associated level of satisfaction (p-value: 0.825).

TABLE 3.2 - SYSTEM QUALITY: RESULTS OF SYSTEM QUALITY OF THE DDS UNDER THE TECHNOLOGY FIT.

\begin{tabular}{|l|l|l|l|l|l|}
\hline $\begin{array}{l}\text { EASE OF LEARNING } \\
\text { WITH THE DDS }\end{array}$ & \multicolumn{4}{l|}{ USEFULNESS OF THE AVAILABLE FUNCTIONS AND FEATURES OF THE DDS } & TOTAL \\
\hline & Neutral & $\begin{array}{l}\text { Somewhat } \\
\text { Useless }\end{array}$ & Somewhat useful & Useful \\
\hline EASY & 3 & 1 & 9 & 17 & $\mathbf{3 0}$ \\
\hline SOMEWHAT EASY & 1 & 0 & 3 & 5 & $\mathbf{9}$ \\
\hline NEUTRAL & 1 & 0 & 0 & 2 & $\mathbf{3}$ \\
\hline TOTAL & $\mathbf{5}$ & $\mathbf{1}$ & $\mathbf{1 2}$ & $\mathbf{2 4}$ & $\mathbf{4 2}$ \\
\hline
\end{tabular}

\section{Pearson chi2 (4) $=2.6561 ; \operatorname{Pr}=0.851$}

As illustrated in Table 3.2, there is no significant association between the ease of use and the usefulness of the system ( $p$ value: 0.851$)$.

TABLE 3.3 - ORGANISATIONAL SUPPORT IN THE SYSTEM IMPLEMENTATION AND UPTAKE: RESULTS OF THE LEADERSHIP SUPPORT DURING THE DDS IMPLEMENTATION AND COMES UNDER THE ORGANISATION FIT DIMENSION OF HOT-FIT FRAMEWORK.

\begin{tabular}{|c|c|c|c|c|c|}
\hline \multirow{2}{*}{$\begin{array}{l}\text { EFFECTIVENESS OF THE } \\
\text { COMMUNICATION BETWEEN } \\
\text { THE LEADERSHIP AND THE } \\
\text { PROJECT TEAM }\end{array}$} & \multicolumn{4}{|c|}{ SATISFACTION WITH THE LEADERSHIP SUPPORT FOR THE PROJECT } & \multirow[t]{2}{*}{ TOTAL } \\
\hline & Neutral & $\begin{array}{l}\text { Prefer not to } \\
\text { say }\end{array}$ & Satisfied & $\begin{array}{l}\text { Somewhat } \\
\text { satisfied }\end{array}$ & \\
\hline DO NOT REMEMBER & 2 & 0 & 2 & 0 & 4 \\
\hline EFFECTIVE & 0 & 0 & 12 & 0 & 12 \\
\hline NEUTRAL & 5 & 0 & 0 & 2 & 7 \\
\hline SOMEWHAT EFFECTIVE & 1 & 1 & 3 & 10 & 15 \\
\hline
\end{tabular}




\begin{tabular}{|l|l|l|l|l|l|}
\hline SOMEWHAT INEFFECTIVE & 3 & 0 & 0 & 0 & 3 \\
\hline TOTAL & 11 & 1 & 17 & 12 & 41 \\
\hline Pearson chi2 (4) $=\mathbf{4 7 . 7 3 2 8 ;}$ Pr= 0.000
\end{tabular}

By contrast, Table 3.3 presents interesting results ( $p$-value: 0.00 ). There is enough evidence at $5 \%$ significance level to conclude that effective communication by the leaders is significantly related to the corresponding satisfaction level observed for the variable leadership support.

TABLE 4 - SURVEY RESULTS OF THE MEDICAL TRANSCRIPTIONISTS' (MTS) RESPONSES TO THE QUESTIONS ASKED ABOUT THE DDS. User satisfaction: results represent the MTs satisfaction of the DDS under the Human fit dimension of HOT-Fit framework.

\begin{tabular}{|l|l|l|l|l|}
\hline $\begin{array}{l}\text { SATISFACTION WITH THE } \\
\text { INITIAL TRAINING } \\
\text { RECEIVED PRIOR TO } \\
\text { USING THE DDS }\end{array}$ & \multicolumn{2}{l|}{$\begin{array}{l}\text { OVERALL SATISFACTION WITH THE CURRENT DDS WHEN COMPARED TO } \\
\text { THE PREVIOUS }\end{array}$} & TOTAL \\
\hline & Satisfied & $\begin{array}{l}\text { Somewhat } \\
\text { Satiffied }\end{array}$ & Somewhat Dissatisfied & \\
\hline DISSATISFIED & 0 & 1 & 0 & 1 \\
\hline SOMEWHAT DISSATISFIED & 1 & 1 & 0 & 2 \\
\hline SOMEWHAT SATISFIED & 1 & 0 & 2 & 3 \\
\hline TOTAL & 2 & 2 & 2 & 6 \\
\hline
\end{tabular}

Pearson chi2 (4) = 5.0000; $\mathrm{Pr}=0.287$

As the sample size for MTs is small, the statistical power of the study is low. None of the tests yield any statistically significant results as seen in Table 4 with p-values greater than 0.05 .

\section{Organisational Fit}

\section{a.) Leadership support:}

Clinicians were asked questions regarding the support from organisational leadership for the DDS implementation and results are mentioned in Section 3, Table 3.3 above. Analysis of the project implementation documents demonstrated that, of the 27 individuals invited to attend demonstrations of the DDS prior to selection, $74 \%(n=20)$ attendance was recorded. This included Senior leaders, MTs, Health Information Managers (HIMs) and some Clinicians. Invitations were broadcast widely with $15 \%(n=4)$ failing to reply and $11 \%(n=3)$ responded but did not attend the demonstrations.

Analysis of the project implementation documents also demonstrated early commitment to the system from senior leaders with $74 \%(n=20)$ of those invited, attending the initial vendor demonstrations of the DDS.
The role of leadership support in implementation success was reflected in respondent's comments that included 'resourcing the project adequately and ensuring passion and support from leadership to make the project outcomes useful', 'leading by example' and 'motivation of the clinical group when change is urgently needed or desired'.

\section{b.) Organisational Culture:}

Examination of project implementation documents revealed that there was an atmosphere of motivation and encouragement for the system implementation backed up by good communication with the stakeholders. The selection process for the new system involved end users in the whole process and the feedback received from the stakeholders who had attended the demonstrations. The document analysis also revealed that the DDS selected aligned best with current organisational IT strategies, was an easy fit with existing practices and enabled growth with Automatic Speech Recognition (ASR) technology and 
integration with the Electronic Medical Records (EMR) system.

\section{Technology Fit}

\section{a.) System Quality}

Survey results for the DDS system quality revealed that, a majority of $78.57 \%$ ( $n=33)$ of the Clinicians use the DDS via computer followed by $16.67 \%(n=7)$ via mobile phone while only $4.76 \%(n=2)$ use the DDS via tablet. The detailed survey results are represented in Table 3, Section 2 above.

A qualitative thematic analysis of the emails raised to the support groups by the Clinicians and the MTs identified that the most common issues faced by users included printing errors, difficulties in resetting passwords, setting up new users and web-browser incompatibilities. Table 5 shows all reasons. b.) Service Quality:

To determine service quality requests for support were analysed. Twenty-two issues were lodged by the end users over the period of four months via email to the support group. Based on the SLA's levels of impact on business, the issues were categorised as having a critical, significant, minimal or normal impact. Out of 22 issues lodged, $77.27 \%$ $(n=17)$ issues met the SLA. Detailed results are shown in Table 6 below.

Results from the survey for Service Quality for the Clinicians and the MTs are shown in Table 7 below. There is no statistically significant association between a preferred mode of communication by the user groups and overall satisfaction of the quality of support they received ( $p$ value: 0.163)

TABLE 5 - SYSTEM QUALITY: MOST COMMON ISSUES FACED BY THE END USERS WITH THE DDS.

Issue type: The most common and frequently occurring issues faced by the DDS end users.

\begin{tabular}{|c|c|}
\hline ISSUE TYPE & ISSUE DESCRIPTION \\
\hline PRINTING ERRORS & $\begin{array}{l}\text { - Dispatch documents not printing or printing } \\
\text { blank; } \\
\text { - } \quad \text { - Double layering of jobs; } \\
\text { - } \quad \text { - Server password timeouts causing printing to } \\
\text { cease completely. }\end{array}$ \\
\hline LOGIN ERRORS & $\begin{array}{l}\text { - Forgotten login details by the users and unable } \\
\text { to reset the password on their own. }\end{array}$ \\
\hline NOTIFICATION ALERT ERRORS & $\begin{array}{l}\text { - } \quad \text { - Unnecessary email notifications for already } \\
\text { completed jobs; } \\
\text { - } \quad \text { - Late notifications for pending jobs for e-sign. }\end{array}$ \\
\hline OTHER MALFUNCTIONS & $\begin{array}{l}\text { - } \quad \text { - Change in work pool priority issues; } \\
\text { - } \quad \text { - Pending e-sign summary reports not available; } \\
\text { - } \quad \text { Functions not available in selected web } \\
\text { browsers. }\end{array}$ \\
\hline NEW FUNCTIONALITY REQUESTS & $\begin{array}{l}\text { - Setting up issues for new user, priority work pool } \\
\text { and work type code. }\end{array}$ \\
\hline
\end{tabular}


TABLE 6 - SERVICE QUALITY; ISSUES LODGED VIA E-MAIL TO THE SUPPORT GROUPS CATEGORISED ACCORDING TO THE SLA.

\begin{tabular}{|l|l|l|l|l|}
\hline BUSINESS IMPACT & $\begin{array}{l}\text { NUMBER OF } \\
\text { ISSUES }\end{array}$ & $\begin{array}{l}\text { PERFORMANCE } \\
\text { STANDARD (DAYS } \\
\pm \text { S.D.) }\end{array}$ & $\begin{array}{l}\text { ACTUAL TIME } \\
\text { TAKEN IN DAYS } \\
\text { (MEAN } \pm \text { S.D.) }\end{array}$ & $\begin{array}{l}\text { NUMBER OF } \\
\text { ISSUES MET THE } \\
\text { SLA }\end{array}$ \\
\hline LEVEL 1: CRITICAL & $13.63 \%(n=3)$ & $0.3 \pm 0$ & $1.11 \pm 1.63$ & 2 \\
\hline $\begin{array}{l}\text { LEVEL 2: } \\
\text { SIGNIFICANT }\end{array}$ & $9.1 \%(n=2)$ & $3 \pm 0$ & $18.5 \pm 18.38$ & 0 \\
\hline LEVEL 3: MINIMAL & $50 \%(n=11)$ & $30 \pm 0$ & $22.30 \pm 28.03$ & 9 \\
\hline LEVEL 4: NORMAL & $27.27 \%(n=6)$ & $90 \pm 0$ & $8.20 \pm 14.84$ & 6 \\
\hline
\end{tabular}

TABLE 7 - SURVEY RESULTS FOR THE QUESTIONS ASKED TO THE CLINICIANS AND MEDICAL TRANSCRIPTIONISTS (MTS) ABOUT THE SERVICE QUALITY PROVIDED BY THE SUPPORT GROUPS OF THE DDS

\begin{tabular}{|l|l|l|l|l|l|}
\hline $\begin{array}{l}\text { OVERALL SATISFACTION } \\
\text { WITH THE QUALITY OF } \\
\text { SUPPORT PROVIDED BY THE } \\
\text { SUPPORT GROUPS }\end{array}$ & \multicolumn{2}{l|}{$\begin{array}{l}\text { PREFERED MODE OF COMMUNICATION WHEN } \\
\text { CONTACTING THE SUPPORT GROUPS }\end{array}$} & TOTAL \\
\hline & Face to face & Email & Mobile & Telephone & \\
\hline NEUTRAL & 0 & 3 & 2 & 6 & 11 \\
\hline SATISFIED & 2 & 11 & 1 & 10 & 24 \\
\hline SOMEWHAT DISSATISFIED & 1 & 1 & 0 & 0 & 2 \\
\hline SOMEWHAT SATISFIED & 0 & 6 & 1 & 2 & 9 \\
\hline TOTAL & 3 & 21 & 4 & 18 & 46 \\
\hline Pearson chi2 (4) = 13.0016; Pr=0.163 & & & & \\
\hline
\end{tabular}

\section{DISCUSSION}

This study confirmed the importance of post implementation evaluation of HIS and the significance of studying the human, organisational and technological dimensions when appraising such implementations. This study was necessary to understand and ensure the promised benefits from the DDS implementation are achieved.

\section{HUMAN FIT}

In terms of User satisfaction, the majority of the Clinicians used the system once in a week and reported an overall satisfaction with the DDS. Satisfaction with the mobile application of the DDS to sign off the letters electronically from anywhere, anytime and improvised system efficiency when compared with the previous access to DDS was noted in the Clinicians' responses. On the other hand, MTs used the DDS daily and demonstrated a mixed response in terms of overall user satisfaction. Frustration with the user interface was the most common reported cause of MTs discontent thus leaving opportunities for further improvement of the DDS in terms of user experience and user satisfaction.

System use was measured by system usage statistics extracted from the database and suggested that, the DDS is most commonly used for producing outpatient letters (high and medium usage) while least usage can be seen in operations and medico-legal reports. This suggest that the 
DDS is fulfilling its purpose for which it was implemented leaving an opportunity for growth and further adoption in the organisation depending on the needs and demand.

\section{ORGANISATION FIT}

The implementation of the DDS was strongly supported by the senior leaders, middle managers and hospital staff as evidenced by the analysis conducted in this study. The active participation of the senior leaders, involvement of the staff and end users of the DDS with an atmosphere of motivation and encouragement led the successful implementation and smooth transitioning of the DDS in the organisation.

Although the implementation was smooth, end users experienced some setbacks when moving to the production environment. Good communication was reported with the internal stakeholders and the vendor but exchanges with Clinicians was challenging due to their clinical demands. Clinicians were encouraged to attend the training sessions to gain a better understanding of the features of the new system and how it could assist them. Additionally, the elimination of the backlog caused due to the previous DDS with the help of outsourcing services supplied by the new vendor proved to be helpful in gaining Clinicians' confidence in the new transcription service implemented.

\section{TECHNOLOGY FIT}

An overall satisfaction for the system quality by most Clinicians was reported; however, at the same time 'teething problems' were identified. The most common problems related to printing errors, malfunctions of the existing system, login and notification errors hampered the daily operational activities. Although Clinicians faced issues, MTs and the internal support groups were the most impacted. MTs, the vital end-users of the system expressed a desire for further functionality around advanced word processing features. This feedback provides a further opportunity for improvement in the DDS functionality. Other comments noted that the 'dictation system was a necessary and good system that was readily taken up' and 'the need and a simple solution made it a successful project'.

In terms of Service quality, most Clinicians reported satisfaction with the service quality but at the same time a mixed response from the MTs was identified. Results based on SLA categories suggest that, although most of the issues were solved by the vendor, the time taken to solve critical issues i.e. Level 1 \& 2 issues according to the SLA was relatively high. While for standard conventional issues i.e. Level $3 \& 4$ according to the SLA, they were solved within the promised timeframes. This leaves a window of opportunity to improve the quality of services and technical support provided by the vendor.

\section{CONCLUSION}

This study utilised an existing comprehensive and validated evaluation framework, the HOT-Fit framework. A clear advantage of using the HOT-Fit framework was its flexibility and ability to be adapted, based on the context and relevance of the study along with stakeholders' expectations. Evidence and reporting of post implementation reviews and the lessons learnt has been scant. This study has demonstrated that a framework, such as the HOT-Fit can successfully be used to measure organisational fit post-implementation of health information systems and to identify where further refinements maybe desirable to ensure that the full benefits of the system are realised.

The overall findings of the study suggest that, the DDS was a good fit within the organisation with some issues on the end-user level. To overcome this and facilitate the smooth functioning of the DDS, communication is imperative so that end users i.e. the Clinicians and MTs understand the system, its functionality and their role in providing timely and high-quality information for clinical care. Although the purpose of this study was not to demonstrate the impact of the DDS on the organisation's business, for example, cost reduction and speeding up the process, this system can have a positive impact for clinicians, the Health Information Services department and the patients. Timely availability of documents in a digitised and shareable format will help in speeding up the patient journey by accelerating the TAT for discharge summaries, outpatient letters and other types of clinical communications. Timely communication to inform the ongoing management and care for patients is critical for continuity of care.

Despite the potential of the DDS in providing efficient administrative services to users and ultimately patients, this evaluation showed that the DDS and implementation process faced various challenges. If the ascertained shortcomings are addressed appropriately, there is a potential of the DDS to function more efficiently in the 
organisation resulting an overall satisfaction and a good user experience with the DDS at the end user level.

\section{COMPETING INTEREST AND RESEARCH FUNDING:}

This research did not receive any funding, nor any competing interests have been declared.

\section{REFERENCES:}

1. Ammenwerth E, Gräber S, Herrmann G, Bürkle T, König J. Evaluation of health information systemsproblems and challenges. Int j med informatics. 2003;71 (2):125-35.

2. Yusof MM. A case study evaluation of a Critical Care Information System adoption using the sociotechnical and fit approach. Int j med informatics. 2015;84(7):486-99.

3. Erlirianto LM, Ali AHN, Herdiyanti A. The Implementation of the Human, Organization, and Technology-Fit (HOT-Fit) Framework to Evaluate the Electronic Medical Record (EMR) System in a Hospital. Procedia Computer Science. 2015;72:580-7.

4. Marques A, Oliveira T, Dias SS, Martins MFO. Medical records system adoption in European hospitals. e J Info Sys Eval. 2011;14(1):89-99.

5. Kilsdonk E, Peute LW, Knijnenburg SL, Jaspers MW, editors. Factors known to influence acceptance of clinical decision support systems. MIE; 2011.

6. Yusof MM, Kuljis J, Papazafeiropoulou A, Stergioulas

LK. An evaluation framework for Health Information
Systems: human, organization and technology-fit factors (HOT-fit). Int j med informatics. 2008;77(6):38698.

7. Mohamadali NAK, Garibaldi JM, editors. Understanding and Addressing the 'Fit'between User, Technology and Organization in Evaluating user Acceptance of Healthcare Technology. HEALTHINF; 2012.

8. Yusof MM, editor HOT-fit Evaluation Framework:: Validation Using Case Studies and Qualitative Systematic Review in Health Information Systems Evaluation Adoption. European Conference on Information Management and Evaluation; 2011 : Academic Conferences International Limited.

9. Yusof MM, Papazafeiropoulou A, Paul RJ, Stergioulas LK. Investigating evaluation frameworks for health information systems. Int j med informatics. 2008;77(6):377-85.

10. Saparova D, Belden J, Williams J, Richardson B, Schuster K. Evaluating a federated medical search engine: Tailoring the methodology and reporting the evaluation outcomes. Appl Clin Inf. 2014;5:731-45.

11. Viitanen J, Nieminen M, editors. Usability evaluation of digital dictation procedure-an interaction analysis approach. Symposium of the Austrian $\mathrm{HCl}$ and Usability Engineering Group; 2011 : Springer.

12. Publishing HH. Technology and Internet Assessment (TIA) scales; Use of Technology (UOT) scale. 2017 [Available from: http://www.hhpublishing.com/_assessments/TIA/scales .html\#UOT 